\title{
Holocene circum-Arctic peatland carbon dynamics
}

\author{
Zicheng Yu and Julie Loisel \\ Bethlehem, United States, 13-15 October 2013
}

Northern peatlands represent the largest biosphere carbon (C) pool in the Earth system, containing about 500 GtC (Gorham 1991; Yu 2012); however, how this large $C$ pool responds to climate change is still poorly understood. The overarching goal of this workshop was to understand climate and other controls on Holocene $\mathrm{C}$ accumulation through a community-wide collaborative and coordinated effort. This Holocene-scale synthesis aims at extending the effort on the peat $C$ synthesis of northern peatlands for the last millennium as reported in Charman et al. (2013).

At the workshop, we reviewed and finalized the newly expanded Holocene peat $\mathrm{C}$ accumulation database that now contains peat property (bulk density, $\mathrm{C}$ content) data for 232 peat cores from 181 sites, and peat $C$ accumulation records for 151 cores from 127 sites (Fig. 1; Loisel et al. in press). This is a major expansion from a previous synthesis of $\mathrm{C}$ accumulation, which combined records from 33 sites in northern peatlands (Yu et al. 2010). Workshop participants also discussed strategies for further analyzing and synthesizing peat $C$ data along with other relevant datasets, including bioclimate records of seasonal temperature, moisture and photosynthetically active radiation (PAR). In order to address the overarching question "what controls Holocene peat $\mathrm{C}$ sequestration?", participants identified eight topical areas that need to be addressed in a coordinated way. Topics for these working groups include peatland carbon database management (leader: J. Loisel); age and peat C uncertainty analysis and modeling (M. Blaauw); Bayesian Monte Carlo Empirical Orthogonal Function (MCEOF) analysis (C. Massa); hierarchical cluster analysis (J. Nichols); lateral expansion data and modeling analysis (L. Belyea); net carbon balance and "true" $\mathrm{C}$ rate reconstructions (Z. Yu); Holocene bioclimate reconstructions (S. Brewer); and peatland carbon - climate analysis (S. Harrison, R. Spahni, and Z. Yu). An improved technique (using Bayesian MCEOF) that accounts for uncertainties in both ages and peat properties is being developed for a spatiotemporal analysis of the $\mathrm{C}$ records. In addition, some groups plan to focus on improving our understanding of important peatland processes, including large-scale lateral expansion (e.g. Ruppel et al. 2013), peat C flux reconstructions at individual sites (e.g. Yu 2011), and PAR controls on peat $C$ sequestration (e.g. Charman et al. 2013).

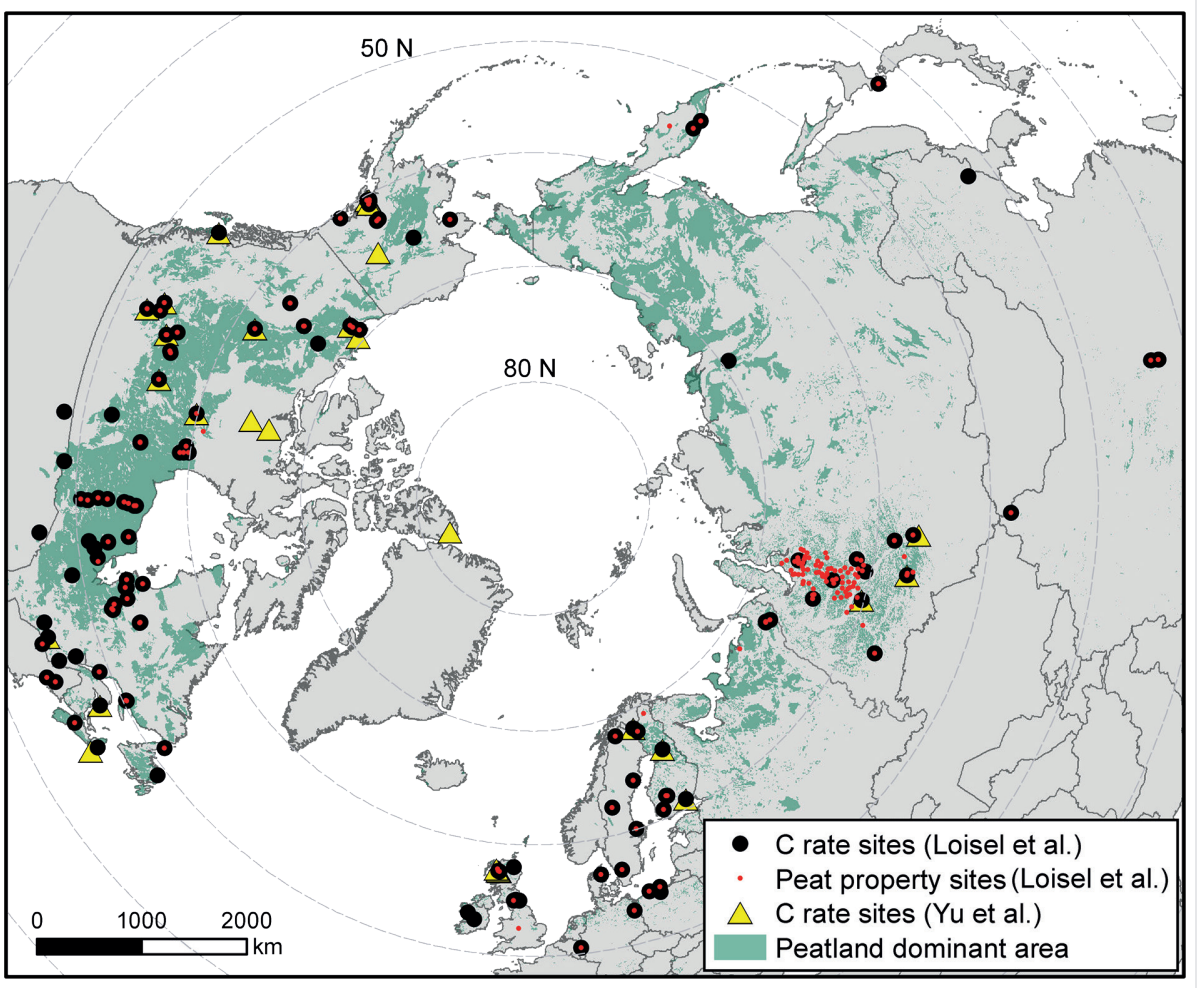

Figure 1: Map showing the locations of peatland sites for $C$ accumulation and peat properties in the database (Loisel et al. in press). Also shown are C accumulation sites used in a previous synthesis (Yu et al. 2010) and the distribution of northern peatlands (green area from Yu et al. 2010). Figure modified from Loisel et al. (in press).
The database used for the synthesis will be archived at https://peatlands.lehigh.edu, and will be linked or ported to other public databases such as Neotoma (neotomaDB.org). New peat $C$ records are to be published in a special issue on "Holocene Peatland Carbon Dynamics in the Circum-Arctic Region" in The Holocene (guest-edited by Z. Yu et al.). In addition to improving understanding of the controlling factors on Holocene $\mathrm{C}$ accumulation, the new database will be useful for calibrating and evaluating Earth system and climate-carbon cycle models (e.g. Spahni et al. 2013) that need to adequately account for the role played by peatlands in the global $\mathrm{C}$ cycle.

The three-day workshop at Lehigh University was followed by a one-day meeting in San Francisco, USA, before the AGU 2013 Fall Meeting. At this meeting, the participants discussed their progress within the working groups and other future research directions. Those included synthesizing and modeling global peat $C$ over the last millennium; synthesizing tropical peat $C$; studying pre-Holocene peat $\mathrm{C}$ accumulation and the structural and functional differences between permafrost and non-permafrost peatlands; and preparing the proposal for the new PAGES "Peat On Earth through Time (POET)" working group.

A total of 25 peatland researchers, including postdoc fellows and PhD students, from seven countries attended the October workshop, and about 40 participants attended the December workshop.

\section{ACKNOWLEDGEMENTS}

We thank the workshop participants for their contributions. The workshops were supported by grants from the US NSF-Arctic Natural Science Program, INQUA and PAGES

\section{AFFILIATIONS}

Department of Earth and Environmental Sciences, Lehigh University, Bethlehem, United States

\section{CONTACT}

Zicheng Yu : ziy2@lehigh.edu

\section{SELECTED REFERENCES}

Full reference list under:

http://www.pages-igbp.org/products/newsletters/ ref2014_1.pdf

Charman D et al. (2013) Biogeosciences 10: 929-944 Ruppel M et al. (2013) Holocene 23: 1596-1606 Spahni R et al. (2013) Clim Past 9: 1287-1308 Yu ZC et al. (2010) Geophys Res Lett 37, doi:10.1029/2010GL043584

Yu ZC (2012) Biogeosciences 9: 4071-4085 